\title{
New Research on Developmental Idealism
}

\author{
Introduction to the Special Issue
}

\begin{abstract}
In this introduction, we offer an overview of developmental idealism (DI) theory and the contributions of this special issue. DI is a collection of values and beliefs about socioeconomic development and its causal links to other elements of societies. Within DI, some societal elements are identified as "modern," inherently good, and helpful to development, while others are identified as "traditional," undesirable, and unhelpful to development. DI theory posits that these schemas spread from Northwest European elites to ordinary people. In turn, people are motivated to adopt "modern" behaviors because they are seen as the means of achieving a good life and socioeconomic development. The articles in this special issue contribute to the empirical investigation of DI theory in a variety of ways. This issue enriches the DI methodological toolkit, demonstrating, for example, that DI measures are valid and reliable and that internet search queries can be used to examine DI. The articles also make strides in assessing the prevalence and nature of DI thinking, from the internet to far-flung geographic locations, including Albania, Kenya, Nepal, and Vietnam. Finally, this issue contributes to identifying pathways for the spread of DI, pointing to national elites, monetary incentives, and television. KEYWORDS developmental idealism, development, ideational, schemas
\end{abstract}

Developmental idealism (DI) is a collection of worldviews, values, and beliefs about socioeconomic development and its causal links to other elements of societies (Thornton 2001, 2005; Thornton, Dorius, and Swindle 2015). At the core of the many values and beliefs that comprise DI are two main propositions. First, societies are at different levels of development and generally move from traditional to modern. And, second, modern elements of societies are not only attainable and inherently desirable, but also causes and consequences of development. The origins of DI are in Northwest Europe. Thus, the societal elements identified in DI as good, modern, and causally related to development are those found in Northwest European societies. Conversely, elements of societies found largely outside Northwest Europe are defined within DI as traditional and unhelpful to development.

DI theory posits that this collection of worldviews, values, and beliefs has been spread around the world by a range of mechanisms, including foreign aid, education, mass media, and the policies and programs of national governments and international organizations. The spread of DI introduces its values and beliefs to societies that have their own values and beliefs, with tension, conflict, and rejection being frequent results. The spread of DI is also a powerful force for global change, as elites and ordinary people often embrace DI and are

Sociology of Development, Vol. 5, Number 3, pps. 225-228. electronic ISSN 2374-538X. (C) 2019 by the Regents of the University of California. All rights reserved. Please direct all requests for permission to photocopy or reproduce article content through the University of California Press's Reprints and Permissions web page, https://www.ucpress.edu/ journals/reprints-permissions. DOI: https://doi.org/10.1525/sod.2019.5.3.225. 
motivated to adopt "modern" behaviors because they are seen as the means of achieving a good life, higher status, and socioeconomic development more generally.

Since its original formulation (Thornton 2001, 2005), DI theory has undergone important changes. Initially, the theory was only about family behaviors and their relationship to development. Thornton (200I, 2005) posited that the spread of DI was an important force for family change, such as older age at marriage and fertility decline. More recently, Thornton and colleagues (2015) expanded DI theory beyond the family to other aspects of societies, including governance, health, religion, and even fashion. This broader formulation posits that DI influences the adoption of democracy, latrines, secularism, and trousers, as well as contraception and cohabitation.

Thornton (200I, 2005) also originally conceptualized DI as a package of values and beliefs, which implied that the elements of DI were disseminated and endorsed — or resistedin a uniform process. More recently, Allendorf and Thornton (2015) characterized DI as a collection of values and beliefs, with ties of varying strengths among schemas. They also emphasized that as DI spreads around the world, local populations accept, modify, and reject different schemas. Thus, the resistance to, adoption of, and influence of DI can vary substantially across contexts.

While DI theory has been around long enough to undergo some revisions, empirical research evaluating the theory has only just begun. The goal of this special issue of Sociology of Development is to expand this empirical work and present new research on DI. Watkins and Hodgson begin the issue with a case study of how Western population specialists and Kenyan leaders facilitated the adoption of DI in Kenya. Jayakody describes how isolated ethnic groups in Vietnam appear to be well acquainted with DI even prior to the introduction of electricity and television. Gjonça and Thornton show that DI is widespread in Albania. Dorius and Swindle find the imprints of DI in English-language internet searches worldwide. Finally, Thornton, Ghimire, Young-DeMarco, and Bhandari demonstrate the reliability and stability of DI views in a Nepali population.

In 2005, Thornton presented a four-part research agenda for empirical investigation of DI and its influence on behavior: develop tools to measure DI; assess the prevalence of DI thinking; identify pathways through which DI is spread and resisted; and examine the influence of DI on behavior (242). The five articles in this issue make important contributions to each component of this research program.

However, before describing the contributions of these articles, it is important to note what this research does not do. Research on DI does not aim to promote the content of DI and takes no position on the veracity or desirability of the values and beliefs that comprise DI. In fact, there is a strong tradition within social science of critiquing such values and beliefs. And while DI theory suggests DI is a powerful force of socioeconomic change, it does not contend that ideational forces are the only ones operating. Material and structural factors are also important influences, which often operate alongside ideational forces.

Methodologically, the articles in this special issue contribute to a diverse DI toolkit. Gjonça and Thornton illustrate how DI items used in surveys with a population-based sample provide rigorous assessment of the prevalence of DI thinking in a specific population. Using similar DI items in another population-based sample, Thornton and colleagues 
demonstrate that these items are both stable and reliable measures of DI thinking, on par with other ideational measures used in American surveys. Dorius and Swindle show how internet data can be used to assess the extent of DI thinking without having to directly ask respondents about DI in a survey. They use internet search queries to look for the hallmarks of DI thinking in people's naturally occurring behavior. Watkins and Hodgson demonstrate how a careful analysis of historical documents and interviews with key informants can uncover the recent history of how and why DI was adopted in a particular context. Finally, Jayakody illustrates how in-depth interviews and focus group discussions about something other than DI, namely television in this case, can document the existence and nature of DI thinking.

Substantively, this special issue makes strides in assessing the prevalence and nature of DI thinking in a range of places. Dorius and Swindle's analysis points to high levels of DI in views of countries' reputations and characteristics among English-speaking internet users worldwide. Gjonça and Thornton document high, but not universal, levels of DI thinking in Albania. Albanians rated countries on development very similarly to the UN's Human Development Index, and most associated "modern" family behaviors with rich countries and believed development leads to family change. However, contrary to DI, many Albanians strongly valued marriage and underrated their own country relative to UN ratings. While it was not their focus, Thornton and colleagues similarly show high levels of DI thinking in a Nepali population. Jayakody demonstrates that even prior to the introduction of electricity and television, isolated ethnic minorities in Vietnam expected television to bring unmitigated benefits. These anticipated benefits largely fell within DI, comprising inculcation of explicitly "modern" behaviors and aspirations related to schooling, health, and family.

This special issue also contributes to the identification of pathways for the spread of DI and the examination of the influence of DI on behavior. Notably, Watkins and Hodgson point to the pivotal role of national elites and monetary incentives in transmitting DI. In the last half of the twentieth century Western population specialists, motivated by the DI belief that low fertility and development are linked, convinced Kenyan leaders to adopt a family planning program. Western education and the belief that adopting family planning would bring development motivated Kenyan leaders, but monetary incentives were also key. Regardless of their own endorsement of DI, Kenyan leaders were motivated to adopt DI-laden family planning policies to access foreign aid. Watkins and Hodgson also document that the adoption and spread of DI in Kenya were not straightforward or consistent. When the Kenyan government first adopted an official family planning program in the I960s and I970s, it was implemented with little energy, and resistance was widespread, even among elites. It was only in the I980s, after a change of government leadership, that the program was energetically supported and became effective. Watkins and Hodgson further suggest that the implementation of DI-laden family planning policies spread DI from Kenyan elites to ordinary Kenyans by the r 990 .

Jayakody's article points to television as another mechanism. She finds that isolated ethnic minorities in Vietnam believed the introduction of television would inculcate DI thinking and modern behaviors. Further research by Jayakody will examine whether those beliefs turned out to be accurate. 
While this special issue takes important steps forward in the research needed to evaluate DI theory, we hope that it also spurs future research. In previous studies using a range of methods-including surveys, ethnographies, focus groups, and historical case studies-DI thinking has been present everywhere researchers have looked. ${ }^{I}$ As this special issue demonstrates, even in relatively isolated countries, like Albania, and in isolated populations in Vietnam, researchers find DI. The world is a very big place, though, and the global extent of DI is not yet established. As noted above, there are also contextual differences in how DI is adopted and which aspects of DI are endorsed, modified, or rejected entirely. This special issue documents some of these intricacies on the internet and in Nepal, Kenya, Vietnam, and Albania. Future research on the global reach of DI should explore these intricacies in even more contexts.

We end with a call for more work examining the influence of DI on the behavior of individuals. This fourth component of empirical research on DI is challenging because it requires longitudinal data. To date, we are aware of results from only one panel survey that has measured DI and its influence on individual behavior (Allendorf and Thornton 2015). We hope that future panel surveys, as well as other research designs, will be used to test the consequences of DI for a range of individual behaviors in multiple contexts.

\section{REFERENCES}

Allendorf, Keera, and Arland Thornton. 2015. "Caste and Choice: The Influence of Developmental Idealism on Marriage Behavior.” American Journal of Sociology 121(1):243-87.

Thornton, Arland. 2001. "The Developmental Paradigm, Reading History Sideways, and Family Change." Demography 38(4):449-65.

Thornton, Arland. 2005. Reading History Sideways: The Fallacy and Enduring Impact of the Developmental Paradigm on Family Life. Chicago, IL: University of Chicago Press.

Thornton, Arland, Shawn F. Dorius, and Jeffrey Swindle. 2015. "Developmental Idealism: The Cultural Foundations of World Development Programs.” Sociology of Development 1(2):277-320.

\section{NOTE}

I. An incomplete list of publications examining DI is available at https://developmentalidealism.org/ pubs/. 